Article

\title{
Contribution of the Vernacular Architecture to the Sustainability: A Comparative Study between the Contemporary Areas and the Old Quarter of a Mediterranean City
}

\author{
Fajer Al Tawayha ${ }^{1, *(\mathbb{C})}$, Luis Braganca ${ }^{2} \mathbb{D}$ and Ricardo Mateus ${ }^{2} \mathbb{C}$ \\ CTAC Research Centre, University of Minho, 4800-058 Guimarães, Portugal \\ 2 Department of Civil Engineering and CTAC Research Centre, University of Minho, \\ 4800-058 Guimarães, Portugal; braganca@civil.uminho.pt (L.B.); ricardomateus@civil.uminho.pt (R.M.) \\ * Correspondence: Fajrty@gmail.com; Tel.: +97-259-530-8880
}

Received: 24 January 2019; Accepted: 5 February 2019; Published: 9 February 2019

check for updates

\begin{abstract}
The strongest point of vernacular architecture is the harmony between environment and buildings. Mediterranean vernacular architecture is harmonized with its local context, including culture and traditions. In addition, it respects environmental and climatic factors, construction materials, and morphology. In the past, people in Palestine built their houses according to their possibilities, needs, available materials, topography, and culture. Without any control from the government or any legal limitations or architects, it was people's architecture, simple architecture. This paper discusses the differences between vernacular and contemporary residential buildings of the city of Nablus at the building scale. The research methodology adopts explanatory qualitative analysis and comparative synthesis methods for both the old and the new buildings of the city of Nablus and considers many parameters of residential buildings such as building materials, interior spaces, openings and vegetation, and the effect of sociocultural values on each. The outcomes of this research allow understanding how the new city residential buildings are far away from the sustainability principles and how the old city is close to it and how the architects and stakeholders could learn from the strategies of vernacular architecture.
\end{abstract}

Keywords: sustainability; building scale; vernacular buildings; Palestine

\section{Introduction}

Today, vernacular architecture is considered a model for sustainable architecture, and the strategies that are now the basis of sustainable construction are derived from aspects and characteristics of this type of architecture [1]. In the past, people in Palestine built their houses per their possibilities, needs, available materials, topography, and culture. Without any control from the government or any legal limitations or architects, it was people's architecture, simple architecture.

Seeing that modern buildings have started to be built in some developing countries' cities, including Palestinian cities, it has become difficult for these cities to maintain their own cultural identities and to achieve a sustainable built environment. Stakeholders and designers in Palestine, as a multi-climatic region, need to consider the variety of climatic and geographic behaviours that should govern the architectural aspects and sustainable themes within the design process [2]. On the contrary, design processes in Palestine have become typical and identical despite the different climate zones within the country. Today, architects and designers do not consider sustainable design principles, especially those related to construction materials and techniques, which help to reach sustainable buildings and cities. It was not the case in the traditional architecture of Palestinian cities, i.e., in the 
urban areas and buildings built before the electrification of the cities. Traditional architecture was more environmentally friendly in the way it utilized vernacular materials and renewable energy to environmentally protect the building occupants from climatic changes and to reduce their reliance on other energy resources.

Moreover, traditional buildings met the social, environmental, and functional needs of their residents. In addition, it employed architectural elements like the traditional courtyard and "Almalgaf" (a chimney for air circulation) to create a comprehensive and sustainable balance in and out of the building.

There are studies that concluded that the neighbour rights between people are strongly affecting the Islamic cities, and these rights or constraints comes from the religious values [3]. Palestinian society is a society with people who believed themselves bound together by strong links such as family ties, ethnic or sectarian religious identity, and many other cultural relations, as is the case in most of the Arab countries, which are strongly affected by such links.

The strongest and the most effective bounds in the Palestinian society are the cultural ones, which come from religious beliefs; religion is very effective and touches every side of the daily life and affects it, such as the habits of clothing, food, the way of thinking and learning, and many other sides, including architecture [4]. If such constraints are not taken into consideration, it will cause negative side-effects on any product of construction, and the current samples of contemporary building omitted this side and failed in achieving the sustainability goals.

To avoid such failed samples, this research is focusing on the importance of socio-cultural values in improving sustainable features of the city by analyzing how such values affected and enhanced the design strategies that shaped the old city. A Palestinian vernacular city was chosen as a case study and as an example of a sustainable city.

The effects of socio-cultural aspects on the city features were analyzed in both urban and building levels, comparing them with the new urban areas from a sustainable point of view. As the main outcome, this study is aimed at presenting the basis to the development of guidelines that could help architects and municipalities of Mediterranean countries, mainly Palestine, to improve the current built environment situation.

\section{Literature Review}

There is no doubt that Mediterranean countries, in general, have some common aspects regarding vernacular architecture, such as climate, materials, and building technologies. Palestine, as a country in the Mediterranean basin, should be linked to its area, and therefore, some studies related to the Mediterranean vernacular architecture are going to be presented here.

One of the most recent studies about Mediterranean vernacular and traditional buildings was done in Cordoba, southern Spain, by Galán-Marín et al. (2018) [5]. This study focused on one traditional element-the courtyard-and tried to improve it by determining the influence of shading this element by analyzing its thermal performance, comparing it with non-shaded courtyards. This study proved, with a quantitative approach, the thermal benefits of the courtyards, and how their positive contributions can be enhanced and integrated into the contemporary architecture.

Fernandes et al. (2014) [1] reviewed the importance of vernacular architecture as a type of construction that should be studied from a sustainability point of view. The study is based on a comparative analysis between the vernacular architecture of two Mediterranean areas-southern Portugal and north of Egypt. The study concluded that Mediterranean vernacular architecture was developed in many perspectives and affected by many factors, such as climatic, environmental and cultural aspects, and that it is possible to find similar vernacular strategies through the Mediterranean regions even if the culture is based on Roman or Arab cultures.

Weber and Yannas, 2013 [6] also highlighted the good thermal performance of vernacular buildings in the Mediterranean climate context and emphasized the benefits of using local materials. This paper concluded that climate is an important issue to consider in building design and that some of the 
cooling passive strategies found in the Mediterranean vernacular architecture were relevant principles to consider in the design of energy efficient buildings. Nevertheless, the current building design is depending most on fossil energy due to the main role that was given to mechanical equipment to control the indoor climate.

In Palestine, few studies have been done on different aspects of vernacular architecture, especially on vernacular strategies affected by sociocultural values and used in different components of residential buildings and comparing them with contemporary residential buildings.

Most of the studies are focused on a specific aspect such as the conservation of the elements of the vernacular architecture or studying the potential of reusing vernacular buildings. For instance; Ijla and Broström (2015) [7] have presented different examples of reused traditional buildings in order to explore the importance of adaptive reuse.

Abdel Hadi (2013) [8] compared old and contemporary buildings in Palestine regarding the specific aspect of thermal performance, concluding that old buildings have a much better thermal performance and cost than contemporary buildings.

Other studies such as Haddad (2010) [2] focused on vernacular and traditional building methods, highlighting that these buildings and solutions should be studied, evaluated, and developed and not copied.

Hussein et al. (2010) [9] highlighted the socio-environmental characteristics of private outdoor spaces in contemporary Palestinian housing, comparing it with the traditional outdoor spaces, with the goal of improving the living quality of future housing design in Palestine. This comparative study was carried out in two different cities located in two different climatic zones of Palestine: Jericho and Nablus. The study was focused on the courtyard concept and in the importance of reintroducing consciously this concept in the design of new residential buildings and in the retrofitting of existing ones. This study was based on a survey that covered 300 dwellings of different housing typologies, such as detached houses and multi-family buildings, which are the most common typologies of contemporary housing in Palestine. As the main conclusion, this study highlighted that the private outdoor spaces are an important and main element for improving and achieving housing sustainability and contemporary outdoor spaces are not designed to meet the inhabitant's needs.

Another comparative study discussed high-density housing in Palestine and the lack of land by comparing between contemporary and traditional typologies and identifying the use of land parameters of traditional housing to improve contemporary housing in Palestine [10]. This study has analyzed different housing, such as courtyard houses, single houses, and attached houses. In addition, it defines the following typologies for Palestinian buildings: i) low-rise-low-density housing, ii) high-rise-high-density housing, and iii) courtyard housing.

Al Tawayha et al. (2016) [11] discussed the differences between vernacular and contemporary cities of Palestine at an urban scale and have presented a comparative study between vernacular and contemporary urban areas of Nablus, in order to allow architects and other stakeholders to identify the principles of the vernacular architecture that can be used in improving the sustainability of new urban areas.

An important study about Middle Eastern vernacular architecture stated that considering vernacular housing prototypes, as a context that is adapted to the constraints of the natural environment, will not definitely lead to the right conclusions regarding appropriate technologies and solutions in general, since it should be analyzed and understood in its specific context [12].

Analyzing the state-of-art is possible to highlight that, in general, most of the current studies in Palestine about vernacular architecture were focused on a specific side or aspect of vernacular buildings, discussing the potentialities and limitations of its use on contemporary construction. This study is exploring different strategies used in vernacular residential buildings with a more comprehensive approach, which include the analysis of how the Palestinian sociocultural values shaped the vernacular buildings of Nablus city and how they can be used to improve the sustainability of new developments. 


\section{Methodology}

The paper applies a qualitative approach through explanatory qualitative analysis and comparative synthesis methods for vernacular sustainable strategies used in Palestinian vernacular architecture at the building scale. The application of this method and the comparison is focused on both old and new residential buildings of Nablus. The comparative analysis was based on a systematic comparison of different design principles used with a focus on building scale strategies to understand similarities and differences.

To build a comprehensive documented knowledge, this study focuses only on comparable architectural components, including the building elements with similar functions (residential buildings), in both the old and the contemporary architecture, which were affected by socio-cultural values.

The old city is divided into five quarters (Figure 1) and the observations and fieldwork were carried out in all of them. The quarters in the old city are mostly residential, with the necessary commercial and workshop areas and stores, which means there are no industrial strips or agricultural areas. All quarters connect at least to one main street.

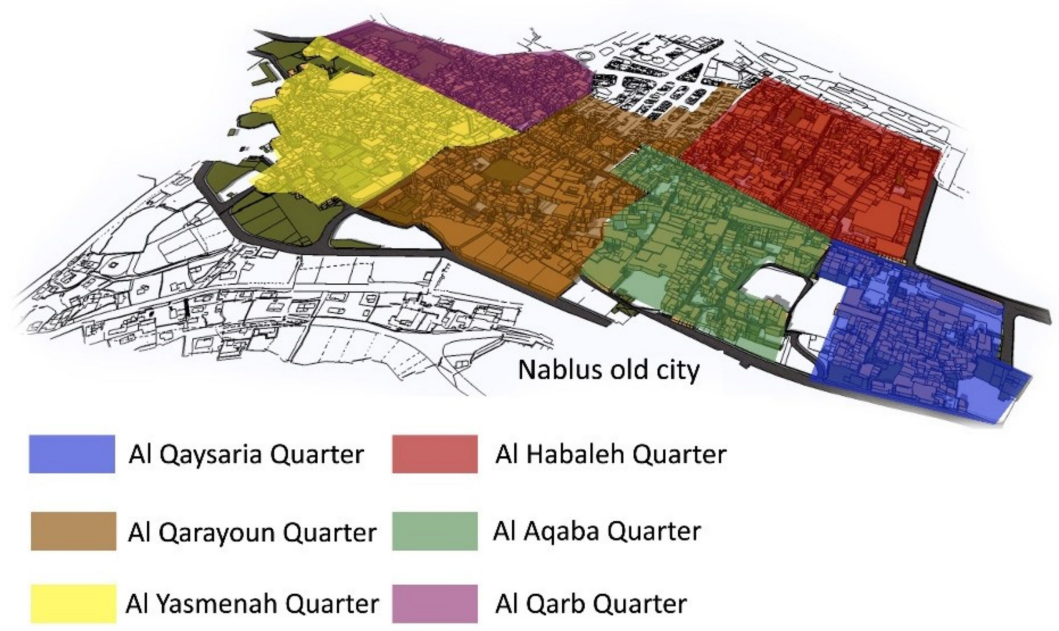

Figure 1. The five quarters of the old city of Nablus.

Pictures and data were collected from each quarter, and a similar number of case studies were analyzed among them (Figure 2).

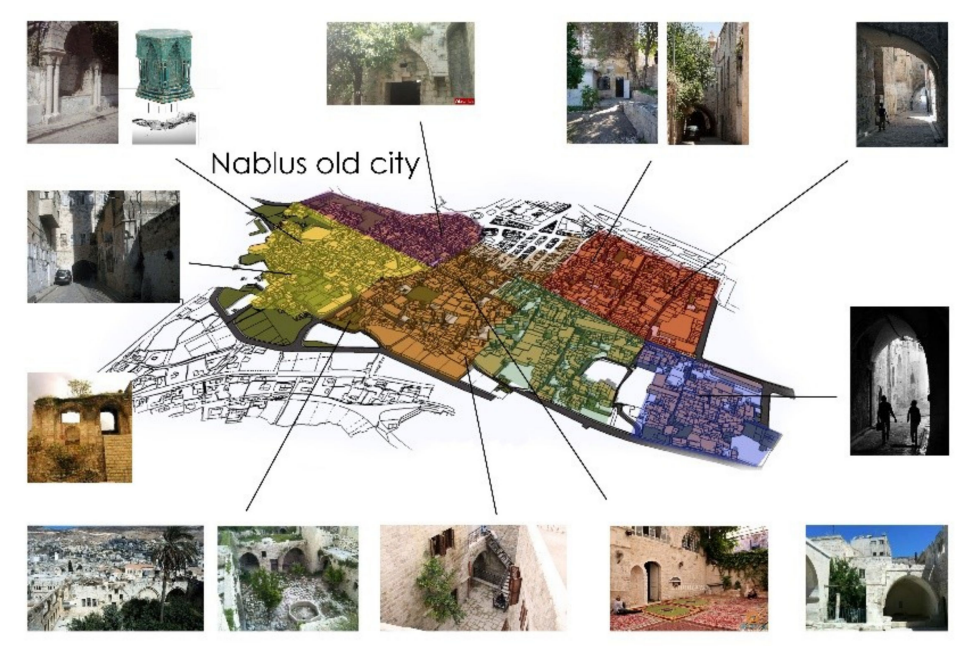

Figure 2. Fieldwork and observations, equally distributed in the five quarters. 
The new urban areas were divided during the fieldwork and site observations into two dominant zones, based on the structural master plan from the Nablus municipality - residential zone A and B. Residential zone A sets some rules regarding the number of floors, rebounds and materials. There, the limitations led for separated villas and isolated buildings. This zone occupies less than $25 \%$ of the city.

The residential zone B covers around $75 \%$ of the city, and it has fewer limitations regarding the floors number, rebounds, and materials. Most people in the city live in this zone. Therefore, the dominant type of buildings in the city is high-rise residential buildings, from 7-16 floors, with about 2-5 apartments on each floor (Figure 3).

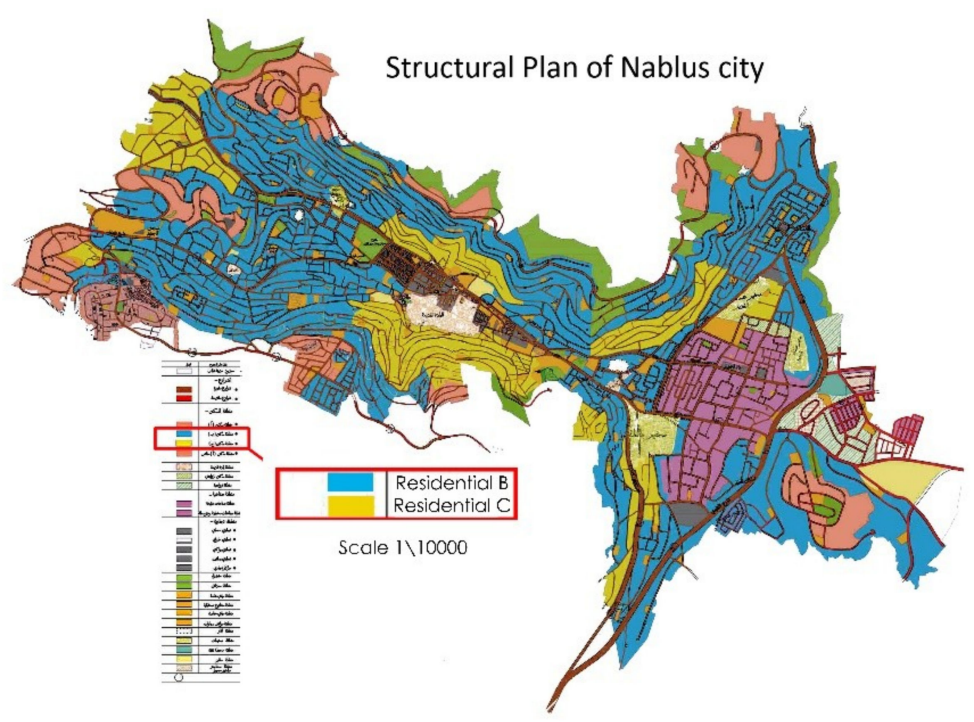

Figure 3. Two residential zones of Nablus new urban areas, zone A and B.

As presented in Figure 4, the fieldwork and site observations were distributed on the two residentially dominant zones of the city, zone A and B. These two residential zones contain the most common building patterns in the new urban areas of Nablus-contemporary buildings could be represented in these two areas.

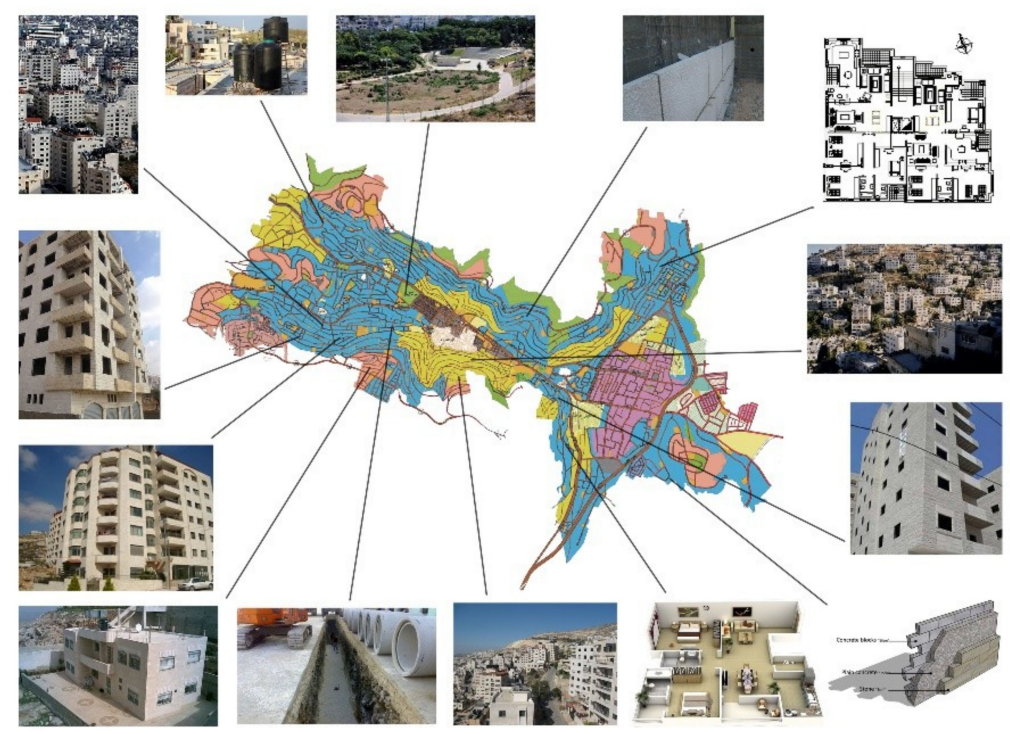

Figure 4. Field work and observations, equally distributed in the city two residential dominant zones. 


\section{Building Level Comparison}

With a deeper insight, the difference grows and expands regarding the achievement of sustainable concepts and observed needs of the people, culture, and place. These differences are clarified in the next comparison graph and tables between the building scale strategies used in the old and new urban areas of the Nablus city, discussing the advantages and disadvantages resulted by the use of such strategies. The comparison is made at the following levels: i) building material, ii) interior spaces, iii) openings and orientation, iv) vegetation, v) building image, and vi) noise transmission (controlling the exposure to noise).

\subsection{Building Material}

Materials used in old and contemporary buildings are different in many properties, such as density, thermal conductivity and heat transfer. These differences affect the thermal performance of the buildings. In this context, Table 1 presents the properties of some vernacular and conventional building materials used in the Mediterranean countries. These materials were used for thermal insulation, to enhance the building thermal performance, for structural aspects, or for all these reasons.

Table 1. Properties of some vernacular and conventional building materials. Adapted from [1].

\begin{tabular}{|c|c|c|c|c|c|c|}
\hline Material & $\begin{array}{l}\text { Density } \\
\mathrm{Kg} / \mathrm{m}^{3}\end{array}$ & $\begin{array}{c}\text { Thermal } \\
\text { Conductivity } \\
\lambda \text {-Value }\left(\mathrm{W} / \mathrm{m}^{\circ} \mathrm{C}\right)\end{array}$ & $\begin{array}{c}\text { Thermal } \\
\text { Storage Capacity } \\
\left(\mathrm{Wh} / \mathrm{kg}^{\circ} \mathrm{C}\right)\end{array}$ & $\begin{array}{l}\text { Heat Transfer Time } \\
\text { Lag for } 250 \mathrm{~mm} \\
\text { Thickness (hour) }\end{array}$ & $\begin{array}{c}\text { Embodied } \\
\text { Energy } \\
\left(\mathrm{MJ} \text { eq. } / \mathrm{m}^{3}\right)\end{array}$ & $\begin{array}{c}\text { Global Warming } \\
\text { Potential } \\
\left(\mathrm{kg} \mathrm{CO} \text { eq. } / \mathrm{m}^{3}\right)\end{array}$ \\
\hline Rammed earth/adobe & $1770-2000$ & $1.00-1.20$ & $0.23-0.30$ & $10 / 9$ & 943 & 38 \\
\hline Concrete bricks & 1200 & $0.39-0.45$ & 0.26 & 6 & 4245 & 357 \\
\hline Stone & $2600-2800$ & $2.3-3.5$ & $0.22-0.24$ & 5.5 & 1300 & 26 \\
\hline Concrete & 2400 & 1.8 & 1.10 & 7 & 1450 & 264 \\
\hline
\end{tabular}

Analyzing Table 1 and comparing with the use of hollow bricks, it is possible to conclude that, although there are some limitations in the use of rammed earth and adobes due to the higher thermal conductivity, there are some advantages such as higher heat transfer time lag and better environmental performance (lower embodied energy ( 1 to 4.5 ratio) and much less Global Warming Potential (1 to 9.5 ratio). Nevertheless, since the external walls of the vernacular buildings are thicker and with greater thermal storage capacity than the walls of the contemporary buildings, some studies concluded that the thermal performance of the vernacular buildings is better than the contemporary ones. For instance, the research carried out by Abdel Hadi, Majd [8] analyzed the differences between the thermal performances of old and contemporary city buildings in Palestine, considering the commonly used building materials and construction systems.

This study concentrated on comparing old and contemporary buildings in Palestine in the light of one main aspect; running and construction costs. Running cost focused on energy consumption or design capacity. This study concludes that old buildings in have a much better thermal performance and cost than contemporary buildings.

These results were summarized in the study through two charts, the result of these two charts were based on tests and simulations on computer programs, the first chart was comparing the total cost "the running cost and constructing" cost of two residential buildings in Palestine, an old and a new building (Figure 5). 


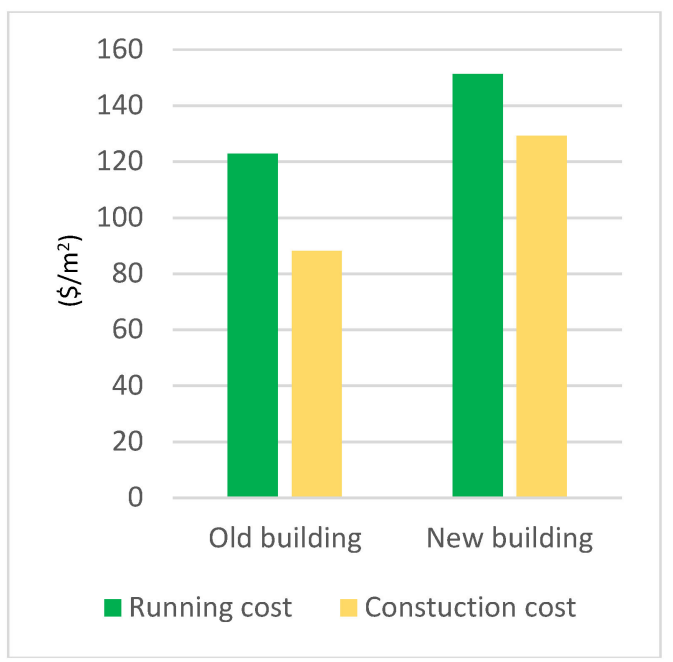

Figure 5. Comparison between the total cost of an old and a new building in Palestine. Adapted from [8].

The second chart was comparing the consumption of electricity per day for cooling and heating each meter square of both buildings "design building capacity" as seen in Figure 6, the result of the two charts proved that natural and local materials used in vernacular buildings could play a good rule in improving thermal performance of contemporary buildings.

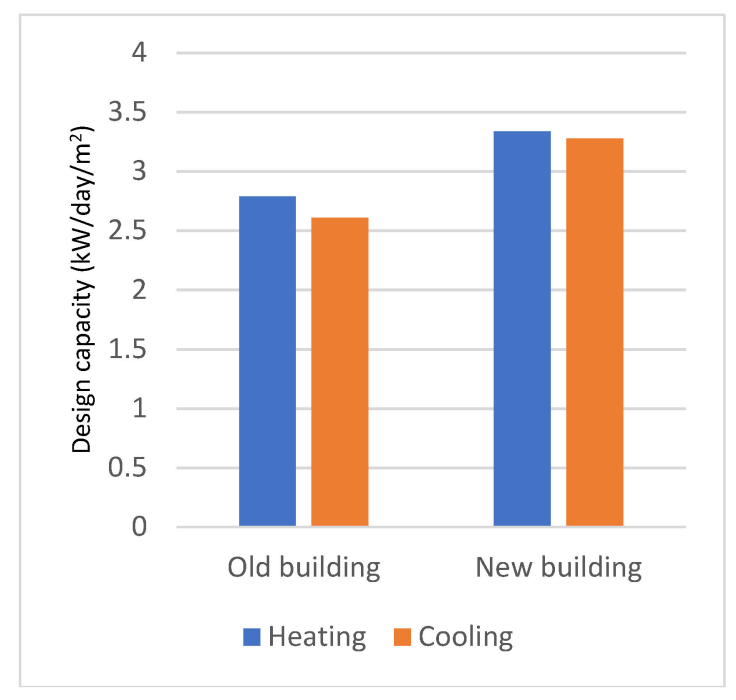

Figure 6. Comparison between the design capacity of an old and a new building in Palestine. Adapted from [8]

Materials in the old city buildings of Nablus mostly depend on natural elements, such as stone, mud and earth. Buildings have thick envelopes. This technology improves the thermal performance and the sound insulation of the buildings, unlike modern or contemporary buildings of the city, which depend on synthetic elements like concrete and steel without any concern for thermal or sound insulation aspects (Figure 7). 

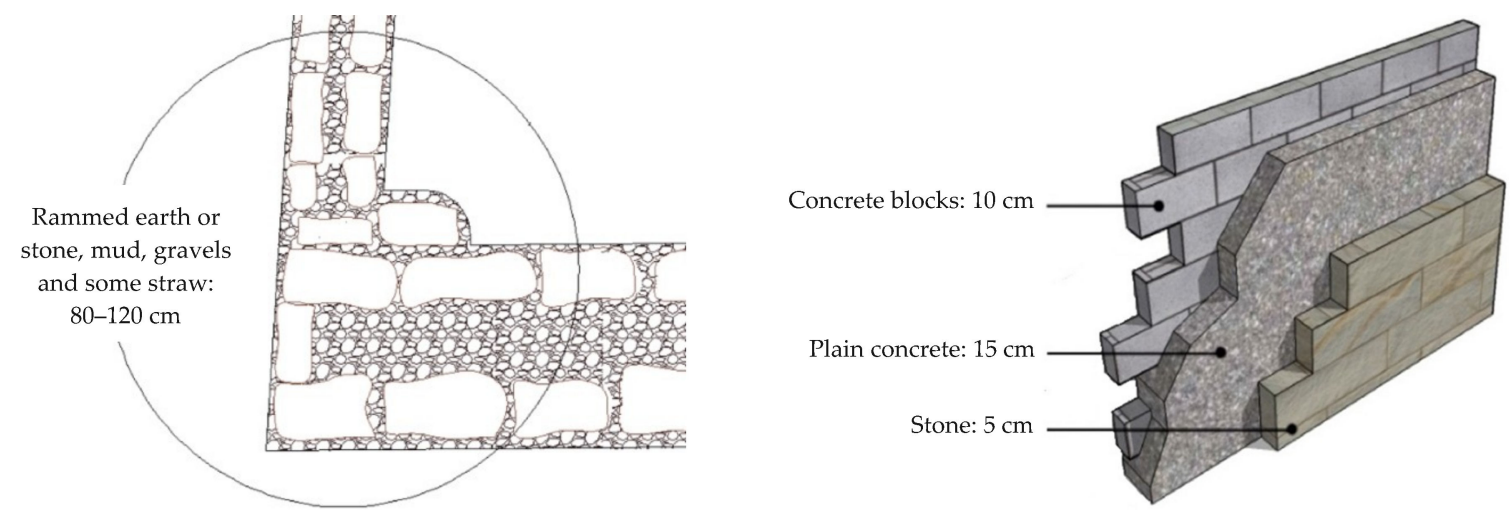

Figure 7. Comparison at the level of the building materials-Old (Left) and New (Right).

\subsection{Interior Spaces}

One of the most important characteristics of the traditional residential buildings in Islamic countries is the courtyard, which is an open sky space created by both environmental and privacy aspects. Privacy was one of the main motivations behind creating and using the courtyard [13]. The courtyard is the most active space in the house, considered as the heart of the house (Figure 8). This open sky space occupied around $20 \%$ of the total area of the house [9].
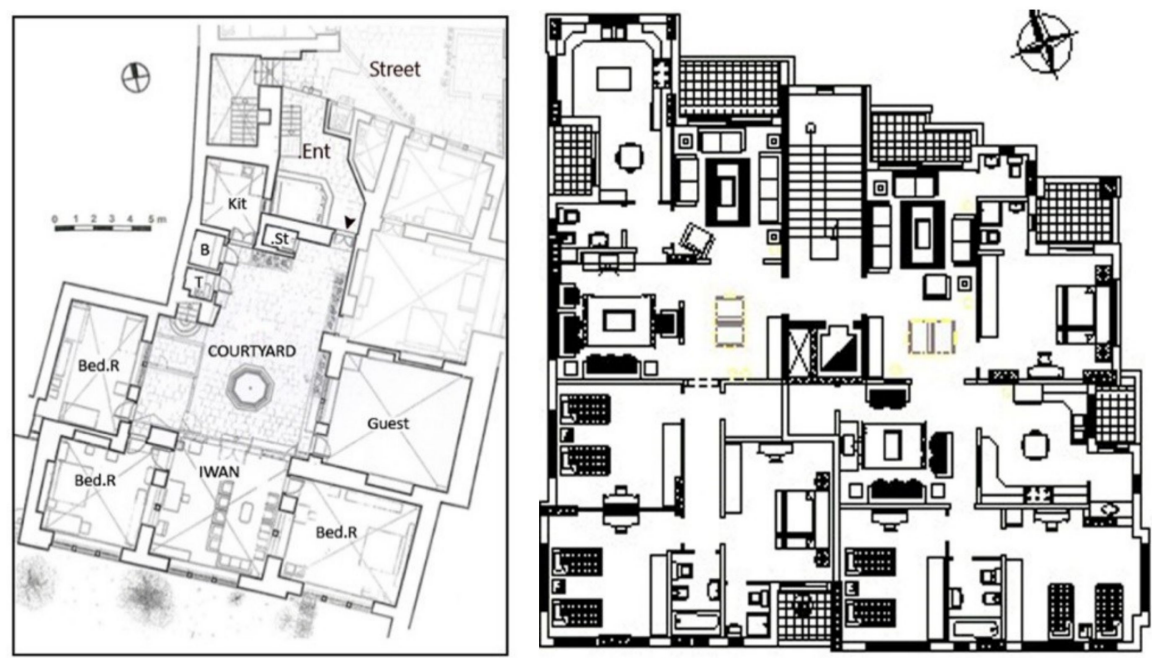

Figure 8. Comparison at the level of the interior spaces-Old (Left) and New (Right)

Environmental aspects were also important regarding the climatic conditions in such area. Hot and dry summer days should be faced with a "radical" and lasting solution. This solution should depend on the design and building integration of passive cooling strategies such as watery and green elements, unlike new or contemporary buildings, were active systems only were included (Figure 9). 

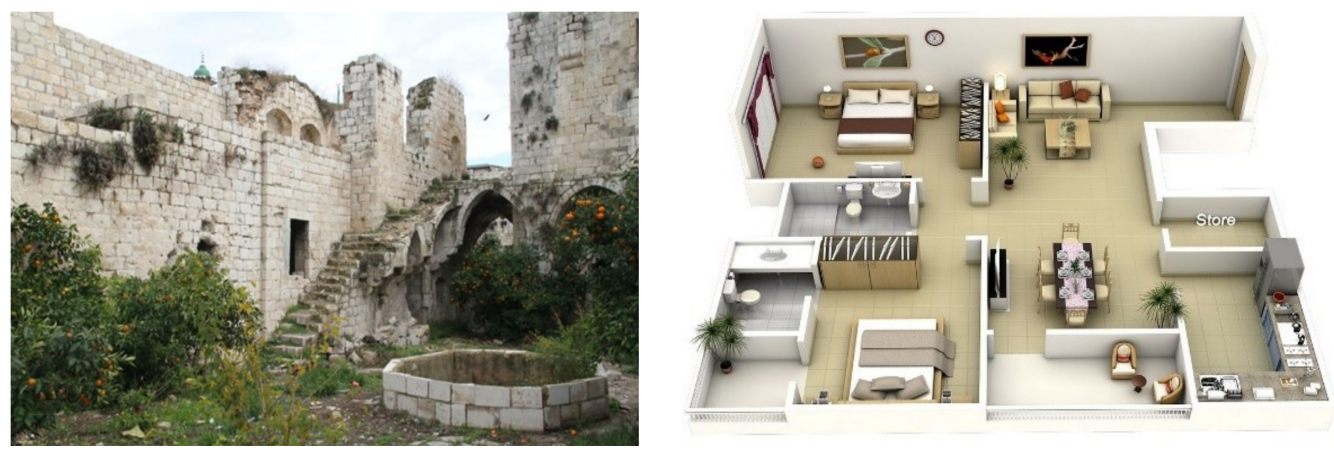

Figure 9. Interior space with passive cooling and lighting systems, Old (Left); active cooling and lighting systems, New (Right).

\subsection{Openings and Orientation}

The old strategies used in such climatic area, characterized by hot summer and cold winter days, depend on reducing heat gains in summer days, and intake sunlight in cold winter days.

Many studies based on computer measurements were done to show the importance and the effect of openings on building thermal performance, such as [12] and [14]. Fernandes studied a building situated in Évora, a city located in southern interior Portugal. The climate there is Mediterranean temperate (Csa-according to the Köppen climate classification) which is the same climate zone of the Nablus area. The study highlights that most vernacular buildings in the region of Évora used small exterior doors/windows as a strategy to mitigate the influence of the climate on the conditions of the indoor thermal comfort of buildings. The findings showed a difference of $7{ }^{\circ} \mathrm{C}$ and $16{ }^{\circ} \mathrm{C}$ between indoor temperatures and the peak outdoor temperatures, which means that the number, size, and the building openings' orientation has great potential on influencing the building thermal performance [14].

Buildings thermal performance can be achieved and/or improved through the adequate design of the building openings, dealing with the size, number, shading, and orientation. The suitable design for this element affects the building thermal performance directly, as it can control heat gains efficiently, allows to take the benefits of the wind breeze and night ventilation in summer days to cool the building, and the intake of sunlight. Window-to-wall ratio is around $10-15 \%$ in old buildings, and fewer and smaller openings were used. In contemporary buildings, the number and the size of the openings are higher, making the ratio more than $35 \%$, without any concern of their compatibility to local climate conditions or any consideration of privacy aspects (Figure 10).
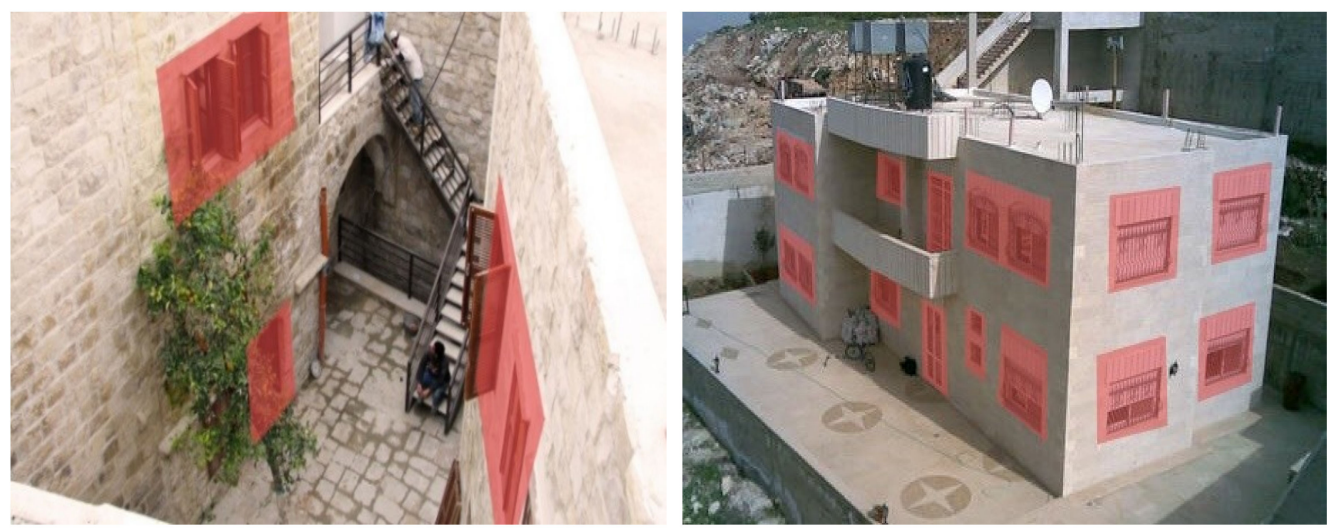

Figure 10. Comparison at the level of the openings-a limited number of building openings to the outdoor spaces, Old (Left); a large number of buildings openings, New (Right).

When talking about privacy, which is an important aspect in Palestine, the number, size and orientation of windows is very important. Ignoring this will potentiate some serious social problems. 
Some solutions were implemented specifically for natural ventilation while avoiding the direct sunlight and maintaining privacy. One of these solutions is the "Mashrabiya", which is an architectural element that acts as a screen (Figure 11). This screen allows wind movement to enter or exit the building during summer days while at the same time prevents sunlight from entering the building, and allows visual privacy for the room behind.

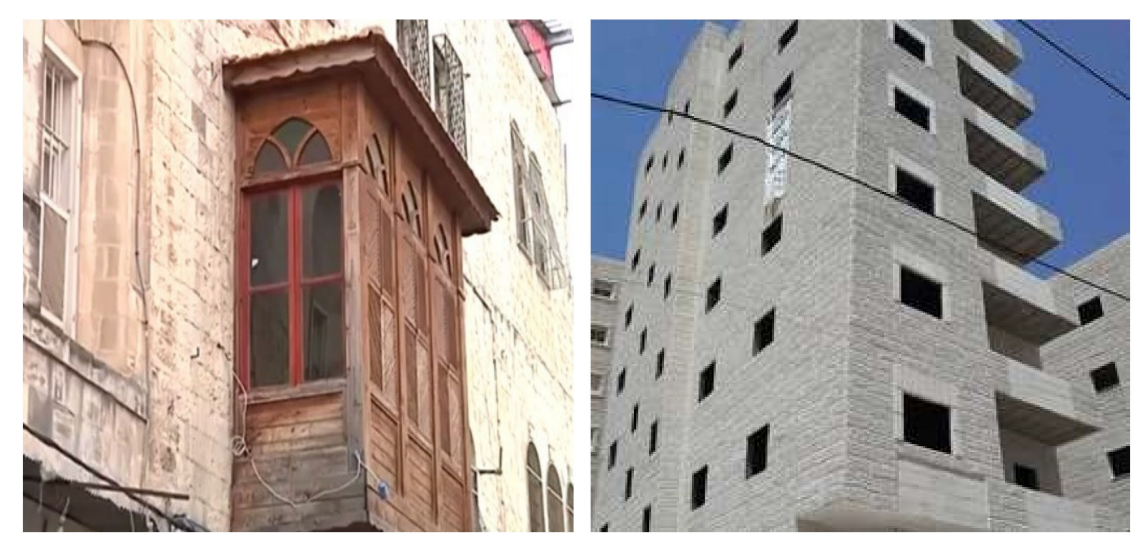

Figure 11. Comparison at the level of the openings, use of shading and privacy elements as the “Mashrabiya," Old (Left); non-shaded openings, New (Right).

Orientation is also an important used strategy. In general, the buildings in the old city are compact and side-by-side and most of the openings are oriented into the courtyard as presented in Figure 12.
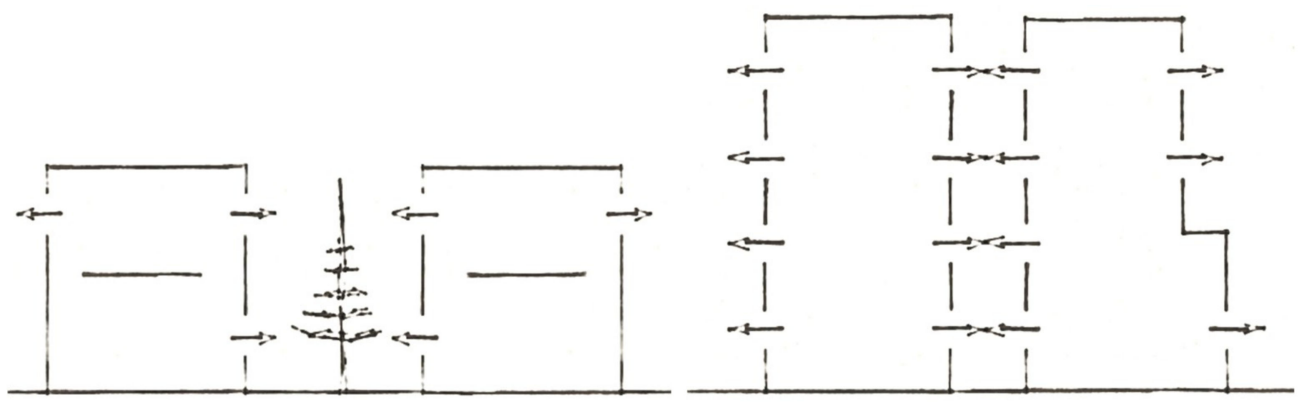

Figure 12. Comparison at the level of the openings, main openings oriented to the inside courtyard, Old (Left); openings oriented to all directions, New (Right).

Most of the outside openings are oriented to the north and the west because of the old city's layout, while the new urban areas are not oriented systematically and have irregular and not pre-planned layout. Privacy cannot be ignored here since the main reason behind the inside oriented openings at the old city of Nablus is to minimize the possibility to be seen or heard by the people outside (Figure 13).

Also, some small openings in the external wall were enough for visual contact and to promote natural ventilation, which was the approach used in the vernacular buildings. In the old city, a kind of perforated facade, named "Kizan", was also used to promote both privacy and cooling purposes. It was generally used on building roofs or terraces, as seen in Figure 14. These pottery facades were used to prevent the users of the space from the hot wind in summer and visual contact with the outside public. The main used material was pottery, as it was cheap, easy to use, and locally available. In a few cases, these perforated facades are made in wood, but pottery is more effective in the cooling process. 


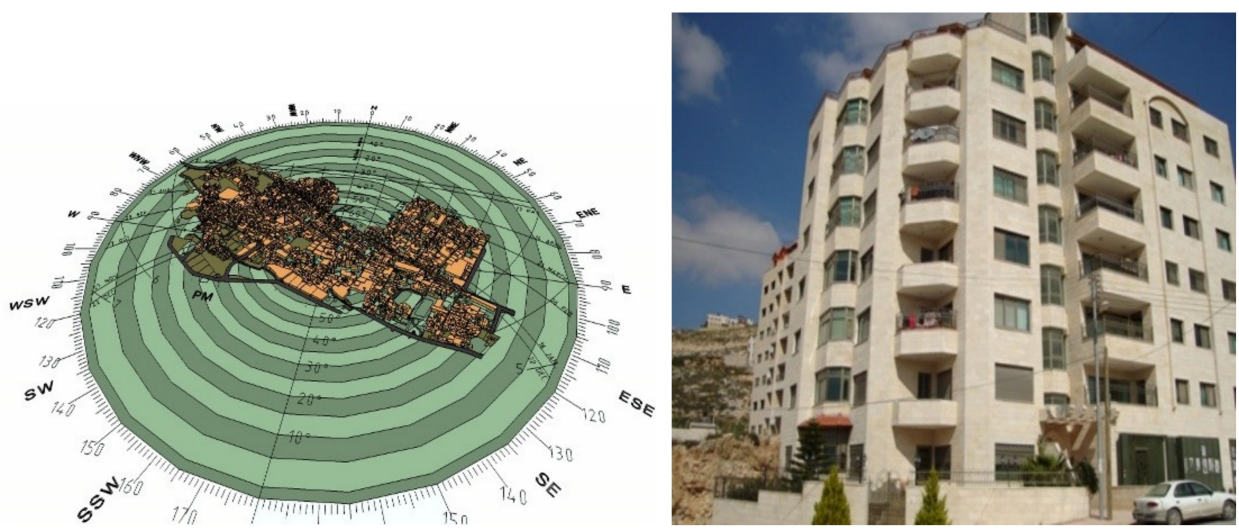

Figure 13. Comparison at the level of the openings, main openings oriented to the inside courtyard, Old (Left); openings oriented to all directions, New (Right).
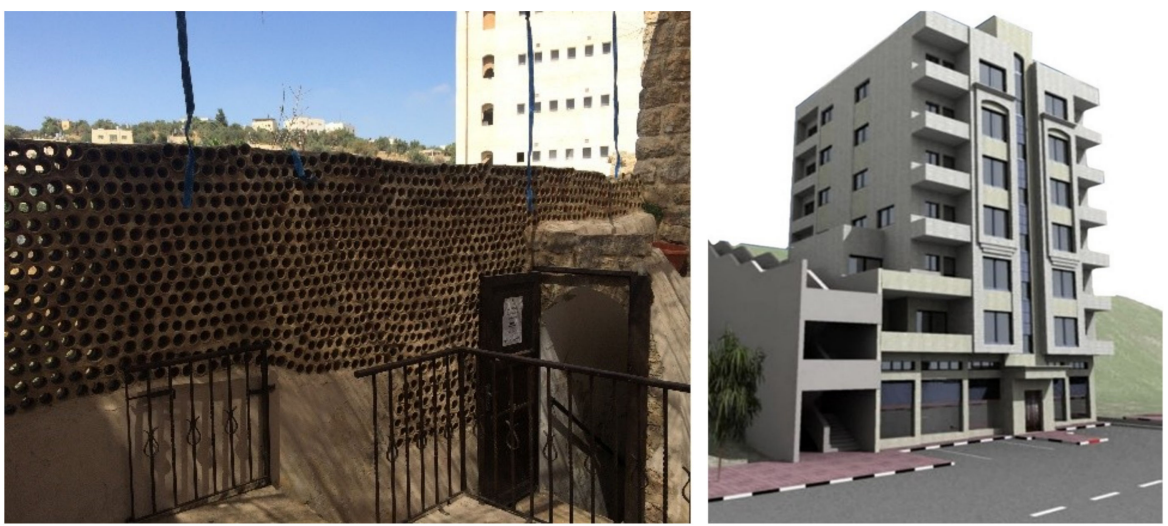

Figure 14. Comparison at the level of the openings, the use of "Kizan" for privacy and cooling purposes, Old (Left); outdoor areas, such as balconies, without visual privacy, New (Right).

\subsection{Vegetation}

Vegetation is useful to provide shading and to increase air moisture via the evapotranspiration process, helping to cool the airflow before reaching the building. This strategy was used in the old city of Nablus in residential and public buildings such as mosques and the "khan". Trees were planted beside windows and doors, inside and outside houses, as seen in Figure 15, providing the building with shadow on hot summer days. In the new urban areas, buildings do not have green elements, being directly exposed to sunlight on hot summer days.
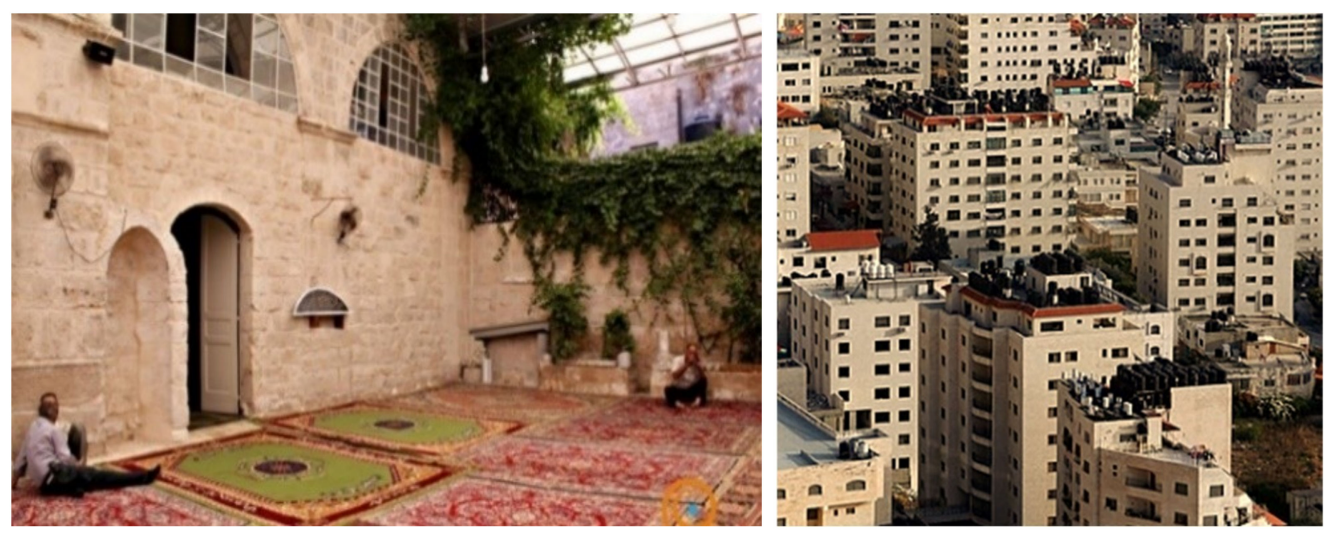

Figure 15. Comparison at the level of vegetation, use of vegetation in the courtyards, Old (Left); absence of vegetation both at building and urban scales, New (Right). 
Also, green elements are effective during the different seasons. In summer, trees are filled with leaves, which provide the shadows needed to reduce sun exposure. In winter, the leaves fall, and more sunlight reaches the building, providing it with the heat on cold winter days. This process has no cost, using only a natural element, unlike the process in the new urban areas where buildings are exposed to sunlight in summer, causing significant of solar gains, and the need to use cooling equipment.

\subsection{Building Image}

The sense of equality among people living in the old cities of Palestine is achieved through the outside image of the buildings. Depending on the modesty social constraint, all the buildings seem to be equal. No one is visible rich or poor from the outside since all buildings have the same characteristics from the outside. As seen in Figure 16, and as mentioned before, inside the buildings, people are free to live however they want within Islamic constraints.

This equality principle is missing in the new urban areas. Rich people have their special deluxe houses, which can be noticed from outside through the used building materials, shape, area, and the number of floors (Figure 17). At the same time, poor people have their simple and modest houses, which can also be noticed from the used building material, shape, building areas, and number of floors. This image is clear from outside the house (Figure 16). This feeling of equality in the old city supported national and local security between people, unlike the modern buildings, where significant differences could be noticed between buildings belonging to people belonging to different social classes.
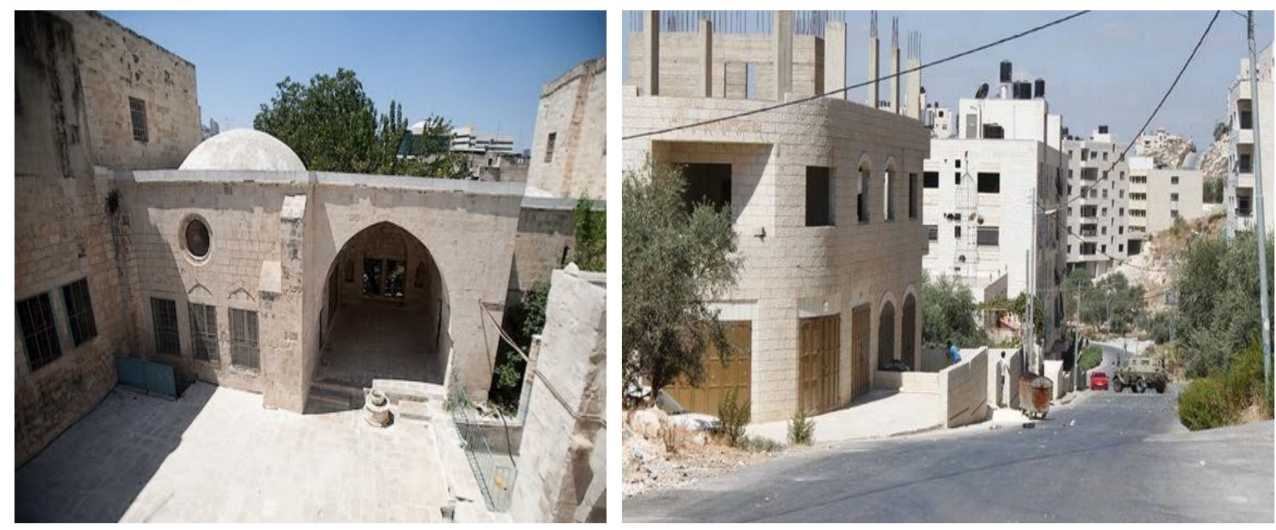

Figure 16. Comparison at the level of the building image, dwellers economic condition was only reflected in the quality of the interior spaces, Old (Left); lower middle and working classes live in multi-residential buildings, New (Right).
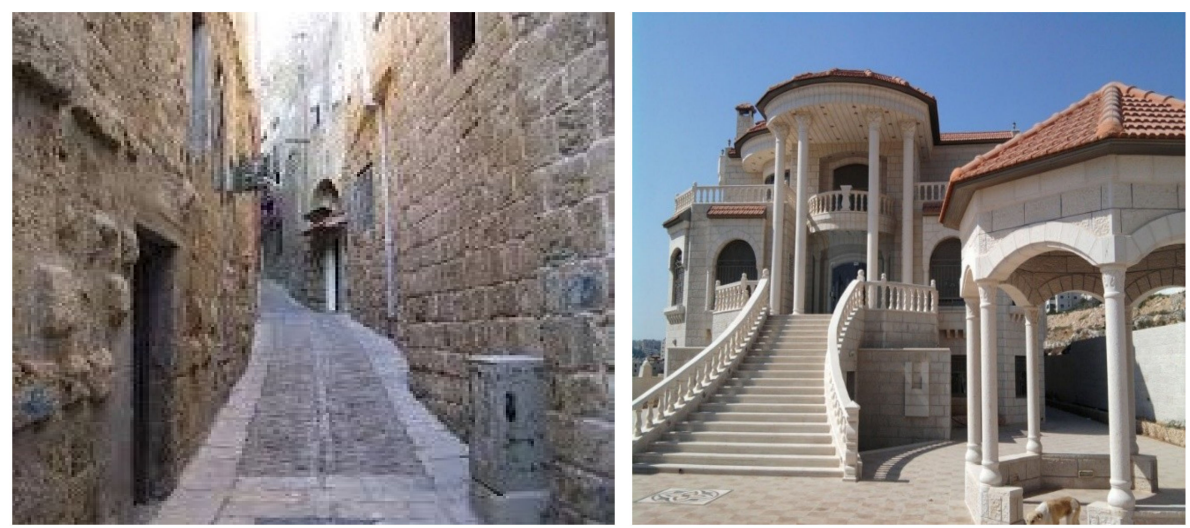

Figure 17. Comparison at the level of the building image, buildings have a similar and simple outside image, Old (Left); the financial situation of dwellers is reflected by the building's image and height and upper-middle and upper social classes normally live in detached houses, New (Right). 


\subsection{Noise Transmission (Controlling Exposure to Noise)}

Many studies focused on the relationship that can exist between urban fabric and outdoor noise distribution, showing that the distribution of road noise depends on the urban form and that there is a strong relationship between urban fabric and road noisescape [15]. The spacing between buildings, cavities, and streets dimensions could play a good effect in distributing outdoor noise since areas between buildings and semi-courts have the lowest noise levels.

Noise transmission (from outdoor and between internal areas) almost did not exist in the old city of Nablus for many reasons. The urban design strategy at the old city depended on low-rise separated cluster houses, which helped in reducing the internal noise transmission, unlike the new urban areas, where multi-residential buildings with side-by-side and overlaid apartments were designed, leading to a continuous element [16], which transmits noise and vibrations between the floors and apartments (Figure 18).
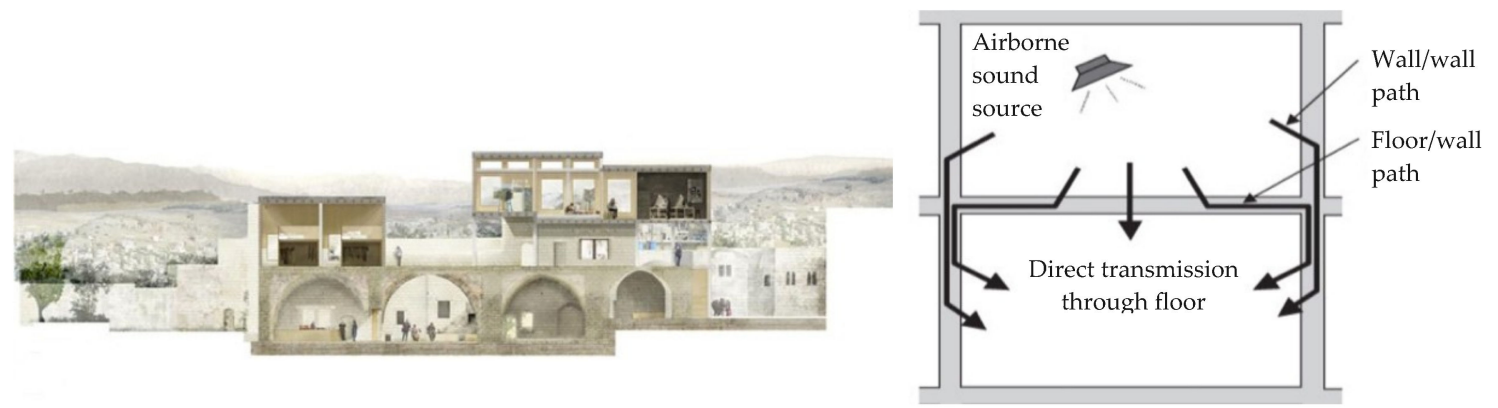

Figure 18. Comparison at the level of the internal noise transmission, low noise transmission through low rise buildings, Old (Left); high level of vertical noise transmission, New (Right).

Also, courtyards helped in reducing the level of internal noise transmission between neighbours to the minimum, due to non-continuous mass and the cavities it produced, on the other hand, the airborne sound transmission between apartments is high, since there is no insulation between those; there is like a continuous space on the horizontal level (Figure 19).
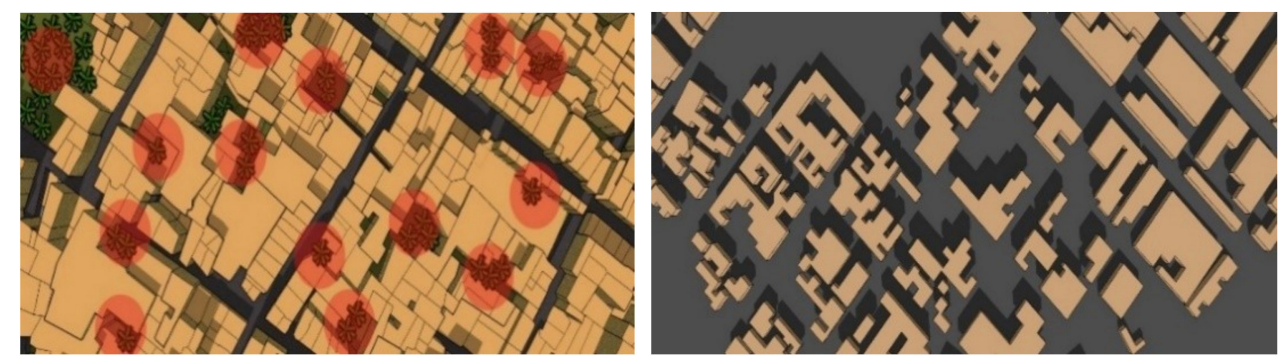

Figure 19. Comparison at the level of the internal noise transmission, courtyards working as a "cavity," a preventive tool of noise horizontal transmission, Old (Left); open streets and separated buildings increase noise from outside buildings, New (Right).

The old city network also reduced noise transmission between the buildings and prevented noise to reach residential units from outside to the lowest or minimum levels through the different scale and use of streets and paths, where cars are not allowed to use all streets and paths.

Streets and city network in the new urban areas enhanced noise transmission. More parts of the buildings were exposed to outside or street noise because of the semi-grid system, since the public streets were used by many types of cars and vehicles (Figures 20 and 21). 

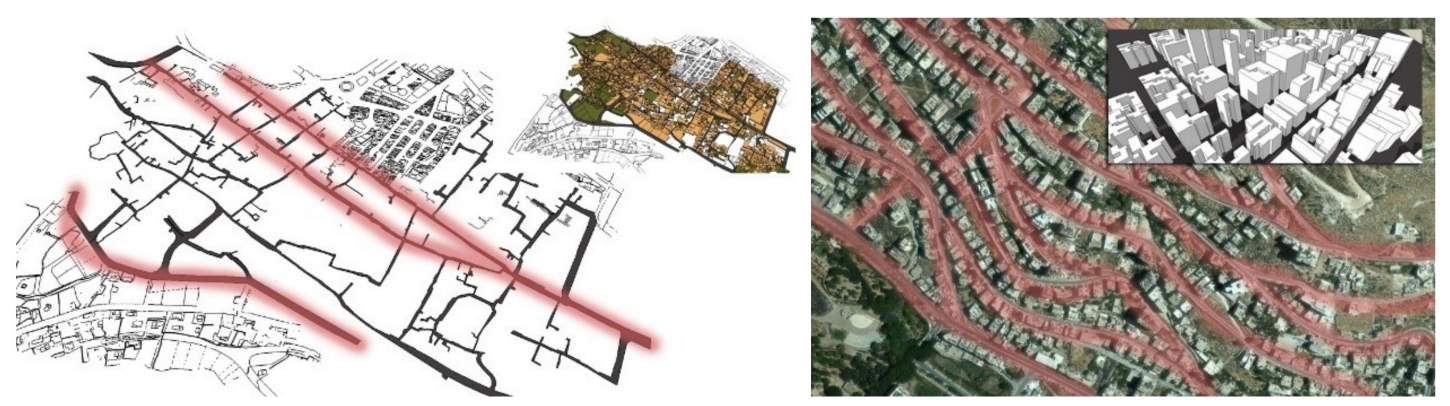

Figure 20. Comparison at the level of the outdoor noise transmission, the different streets types allowed to decrease noise transmission, Old (Left); Public and not classified streets helped to increase noise transmission, New (Right).
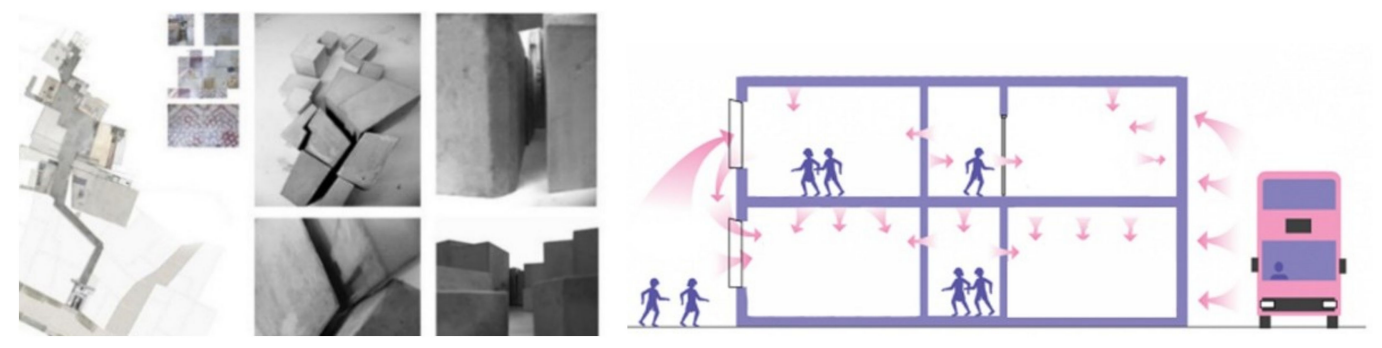

Figure 21. Comparison at the level of the outdoor noise transmission, pedestrian paths without vehicles also helped to decrease outside noise, Old (Left); allowing vehicles to use all streets helped to increase outside noise, New (Right).

\section{Presentation and Discussion of Results}

The results presented in this paper are innovative since, so far, there were no previous comparative studies focusing the comparison between the performance of the old (vernacular) and new buildings of the Palestinian cities.

Analyzing and discussing this situation is very important since there are some problems related to the implementation of some international design models that are not suitable to the Palestinian climate and sociocultural contexts. Among others, the use of imported design models is leading to the abandonment of some outdoor areas (which are not used or maintained), to the increase in costs related to buildings operation and maintenance, and to some after built adaptations of the dwellings by the owners or tenants to satisfy some important functional requirements in Palestine, such as the privacy [17].

Through the comparative approach presented in the previous chapter, it was possible to highlight some features of the vernacular buildings, located in the old quarter of the city of Nablus, which can contribute to better buildings at environmental, sociocultural, and economic levels. Nevertheless, an adequate building design will come from a proper integration between old and modern building features. For instance, there are some features of the old buildings that cannot be used in the design of new buildings or urban areas, since they do not fit the requirements of the modern standard of living.

Based on the outcomes of this study it is possible to highlight some strategies that are missing in contemporary building design and city planning. Those strategies are summarized and discussed below at the following levels: i) building material, ii) interior spaces, iii) openings, iv) vegetation; v) building image, iv) and noise transmission and exposure.

\subsection{Building Material}

Materials used in buildings in the old city depended on natural, local, and sustainable materials. No materials were imported from outside the region, and no materials were processed or manufactured. The most commonly used building materials were mud and earth with thick dimensions. It allowed 
improving the buildings' thermal and acoustic performances and enhancing sustainability aspects such as economic aspects in the city.

The new urban areas and the modern or contemporary buildings are very different. They depend more on synthetic materials, such as concrete and steel, which are not sustainable materials, not local, and hard to reused or recycled in Palestine. The construction elements based on synthetic materials are also poor regarding thermal or noise insulation if used alone without adding insulation materials.

\subsection{Interior Spaces}

It was clear the great difference between the interior spaces of the old city houses and new city apartments. Privacy in the old city was very important and the house design was depending mainly on this constraint.

More constraints affected the interior spaces in the old city of Nablus, such as modesty and hospitality, and the courtyard house was one of the many solutions responding to these values. Also, the temperature of these interior spaces was important: keeping the indoor temperature suitable for daily life was achieved with suitable and environmental, lasting, or passive solutions.

The contemporary houses depend more on financial aspects, ignoring the other important aspects. People want to build a cheap house, or a cheap place to stay, whatever the result, regardless of whether or not this house fits their culture or beliefs. As a result, the houses were designed without any care about sociocultural values, interior environment, or any concern regarding the environmental impacts.

\subsection{Openings}

Openings are very important in the design process, namely their area, location, and orientation. In the old city houses, it was clear that people considered that opening are very important either for privacy aspects or passive cooling strategies. The number of openings was limited to control heat gains and losses, and oriented to collect the needed cool breeze in hot summer days, and sunlight in cold winter days, besides achieving the suitable level of acoustical and visual privacy. On the other hand, in contemporary buildings, this strategy is missing, as openings were located without any concern regarding the sunlight or wind direction in summer and winter, and privacy was not achieved at any level.

\subsection{Vegetation}

Green elements, in general, are very important at the city and building levels, and even if trees were planted to achieve a building level goal, they also have a positive contribution at the building level. In the old city and considering the building level, trees and plants were used for several purposes, such as privacy, as a passive cooling approach during hot summer days and to improve the air quality in the city.

Vegetation is missing in the new urban areas and buildings. It is difficult to plant trees in the new apartment blocks because there is no suitable place, and the local governments are poor and cannot allocate a place for a green area for the neighborhoods. As a result, shading and passive cooling are missing in the new urban areas and therefore the city tends to become unhealthier.

\subsection{Building Image}

The commitment with the modesty, one of the religious constraints in Palestine, led to the image of the old city buildings, where the feeling of equality is dominant. From the outside, the buildings are similar and almost the same and rich and poor people have buildings with a similar outside aspect. That would reduce the manifestations of envy and antagonism among people in the society. Inside the house, people could live free and give the interior space the image they want. This is missing in the new urban areas and buildings. The outside image of the building depends on the financial condition of the owner, and that can be easily noticed in the new urban areas. 


\subsection{Noise Transmission}

As seen above, the strategies of the old city and the contemporary city strongly affects the noise exposure and transmission. The old city strategies helped to reduce noise to minimum levels. This was achieved by avoiding the main roads to pass through the residential areas, depending sequentially to narrower or pedestrian roads in the areas next to residential units. With such formation, noise nuisance related to outdoor noise is very low in the residential units of the old city.

Moreover, the concept of "Housh" or yard, which is a private area with a refracted entrance, also reduces the noise arising from the different activities to the neighbours. Also, the courtyard, where most of the families' social activities take place, is separated from the neighbours, preventing noise transmission between buildings.

At the contemporary buildings, the activity area and the living room are not separated, thus the noise is simply transmitted through walls, doors, and floors to the other dwellings. The contemporary city is also designed and based on a grid system, depending on separated buildings surrounded by streets from at least two sides. Thus, buildings are surrounded by roads, generally main roads, and since the noise insulation of the façade is usually insufficient, there are a lot of noise nuisance problems in the dwellings of the new urban areas.

\section{Guidelines to be Considered in the Design of More Sustainable Buildings}

Based on the previous analysis and comparison between the old quarter and the new city area of Nablus, some guidelines could be developed. These guidelines aim to support decision-making in the designing stage of new residential areas and buildings in Palestine, in order to promote the integration of the best design principles identified both in the new and old city areas that could contribute to the development of a more sustainable built environment. These guidelines are also suitable to be used in the design of residential areas and buildings in other Mediterranean cities that have similar climatic conditions, culture and religion.

The guidelines concluded from the previous parts could be summarized and classified within sustainable categories: innovation and design; awareness and education; indoor environmental quality; materials and resources; energy and atmosphere; water efficiency; sustainable sites and; location and linkages (Figure 22).
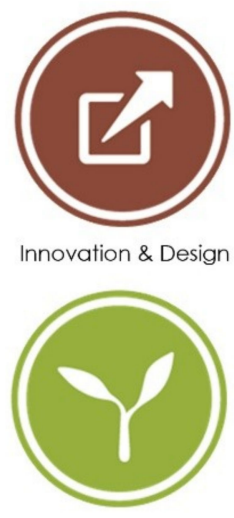

Sustainable Sites

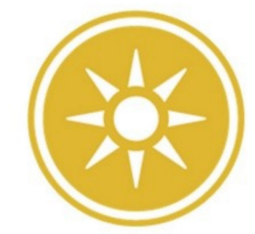

Energy \& Atmosphere

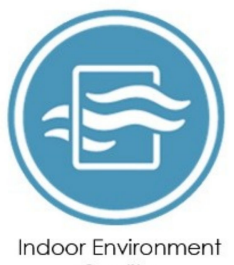
Quality

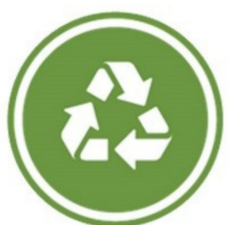

Materials \& Resources

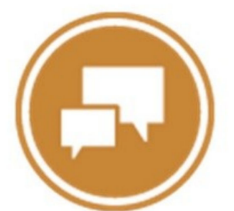

Awareness \& Education

Figure 22. Core sustainable categories normally considered in building sustainability assessment methods. Adapted from [18].

Some of the presented guidelines are also oriented to building owners or promoters since they are the ones responsible for the budget decisions, which play an important role in the design decision process. 
As a common practice in this part of the world, building designers follow the requirements of the owner while designing a house, but of course, people are not aware of all the details during the design process. Therefore, these guidelines are important for both architects and dwellers.

Table 2 summarizes the suggested guidelines, organized according to the sustainability categories which fixed Palestine as a special case.

Table 2. Suggested guidelines within each sustainable category.

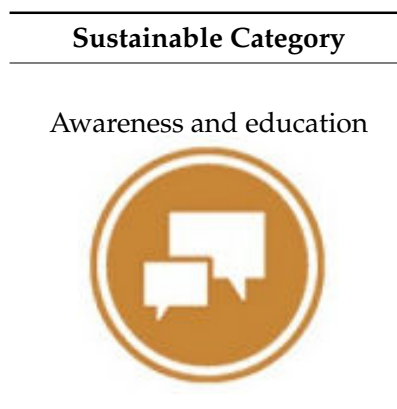

\section{Suggested Guideline}

1. Owners and/or potential occupants should be involved since the early design stages and participate in the decision-making processes.

2. Differences between the inhabitant's social conditions must not be noticeable from the external building image since people must feel a sense of equality in the society or state in which they live.

3. Building design should respect and enhance the local society's people sociocultural aspects, such as privacy, modesty, etc., especially while designing a building for conservative inhabitants such as Arab and Muslim people.

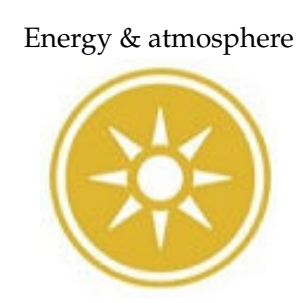

4. Buildings in the Mediterranean basin countries should benefit from the sunlight in the long sunny days for energy production, through providing the energy needed for cooling and heating. Many technologies could be used here such as solar thermal collectors and PVs.

5. Heat gain could be enhanced by studying and analyzing the orientation and the height of the openings, courtyards, roof gardens, dynamic and perforated envelopes; these strategies to capture the solar radiation during winter must be a priority.

6. To improve passive cooling and to reduce the use of air conditioning systems, it is possible to consider some principles already used in the vernacular construction, such strategies such as "Kizan" or "Malqaf".

7. Screens such as "Mashrabiya" or "Kizan" improve building thermal performance either in cooling or heating the building.

8. The building materials should depend more on the local environment, selecting sustainable and local materials instead of imported synthetic materials. Preference should also be given to materials that can be recycled and reused such as building stone.

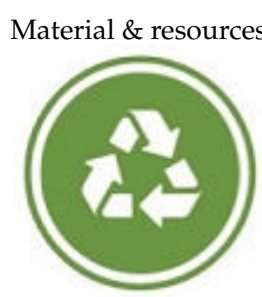

9. New insulation materials and technologies should be developed and used to improve indoor environmental quality (IEQ), instead of depending on mechanical and electrical tools to improve indoor environmental quality.

10. Light colours should be used especially on building roofs and facades to decrease heat gain in hot summer days and to reduce the heat island effect.

11. Give preference to local, available, and cheap materials such as stones and mud, as these promote sustainability by reducing the potential environmental impacts and costs. Nevertheless, such materials should be used parsimoniously when needed. 
Table 2. Cont.

\begin{tabular}{|c|c|c|}
\hline Sustainable Category & & Suggested Guideline \\
\hline & 12. & $\begin{array}{l}\text { Plants and trees should be used for shading buildings and streets } \\
\text { around the city. }\end{array}$ \\
\hline \multirow{9}{*}{ Indoor environment quality } & 13. & $\begin{array}{l}\text { Interior spaces should fit the user's needs and size; space should be } \\
\text { compatible with the number of family members; to achieve that, } \\
\text { analysis followed by bubble zoning should be done. Imported and } \\
\text { non-compatible plans or interior spaces with people's needs and culture } \\
\text { would drive social problems. }\end{array}$ \\
\hline & 14 . & $\begin{array}{l}\text { Interior spaces should respect sociocultural aspects such as privacy and } \\
\text { modesty. Interior spaces are the place where people live most of their } \\
\text { time, and it should be compatible with their believes and culture. }\end{array}$ \\
\hline & 15. & $\begin{array}{l}\text { It is recommended to use green elements in the house indoor spaces } \\
\text { such as balconies and living areas, and on building facades for healthy } \\
\text { and cooling aspects. }\end{array}$ \\
\hline & 16. & $\begin{array}{l}\text { Building openings should be oriented to benefit from sunlight in cold } \\
\text { winter days, and the wind in the summer hot days. Sun and the wind } \\
\text { should be studied and analyzed. South sunlight is important in Nablus } \\
\text { winter, the north wind is important in Nablus summer days. }\end{array}$ \\
\hline & 17. & $\begin{array}{l}\text { Building openings should respect privacy levels, the height and the } \\
\text { number of openings should be analyzed and studied to achieve } \\
\text { different levels of privacy. }\end{array}$ \\
\hline & 18. & $\begin{array}{l}\text { In addition to buildings height, openings should not harm neighbours } \\
\text { by not respecting their privacy in all its levels. For instance, people } \\
\text { should not see their neighbours house or part of the house through } \\
\text { an opening. }\end{array}$ \\
\hline & 19. & $\begin{array}{l}\text { Buildings openings are very important in enhancing building thermal } \\
\text { performance; by studying the position of the opening, the height and } \\
\text { the sun or the wind it could collect during summer or winter. }\end{array}$ \\
\hline & 20. & $\begin{array}{l}\text { Green elements are important in improving the dweller's health. } \\
\text { Regarding psychological aspects, people feel relax and close to nature } \\
\text { when green elements are available in the house, if possible, green } \\
\text { elements could be placed in courtyards, balconies, and outside surfaces. }\end{array}$ \\
\hline & 21. & $\begin{array}{l}\text { Plants and trees used in houses aid achieving interior thermal comfort, } \\
\text { because of the leaves of the plants and trees work as an evaporative } \\
\text { cooling tool. }\end{array}$ \\
\hline
\end{tabular}

Buildings should be designed to avoid noise transmission though the interior spaces and cavities; cavities help to reduce noise transmission between buildings, courtyards are a good example of such cavities.

As mentioned before, these guidelines would help designers during the design process to enhance it to be a sustainable one. Designers pass through many stages to produce the final product, starting from the designer himself, passing through establishing the program of the project, and ending with producing the design solution. Designers study this process during their education and it represents their language, therefore, these guidelines should address designers (architects, interior designers, and landscape architects) in their own language to be more effective.

The next diagram presents the design process stages including effective sustainable categories on each phase, this could save time and effort during the design process, designers could use this diagram as a manual for the guidelines (Figure 23). 


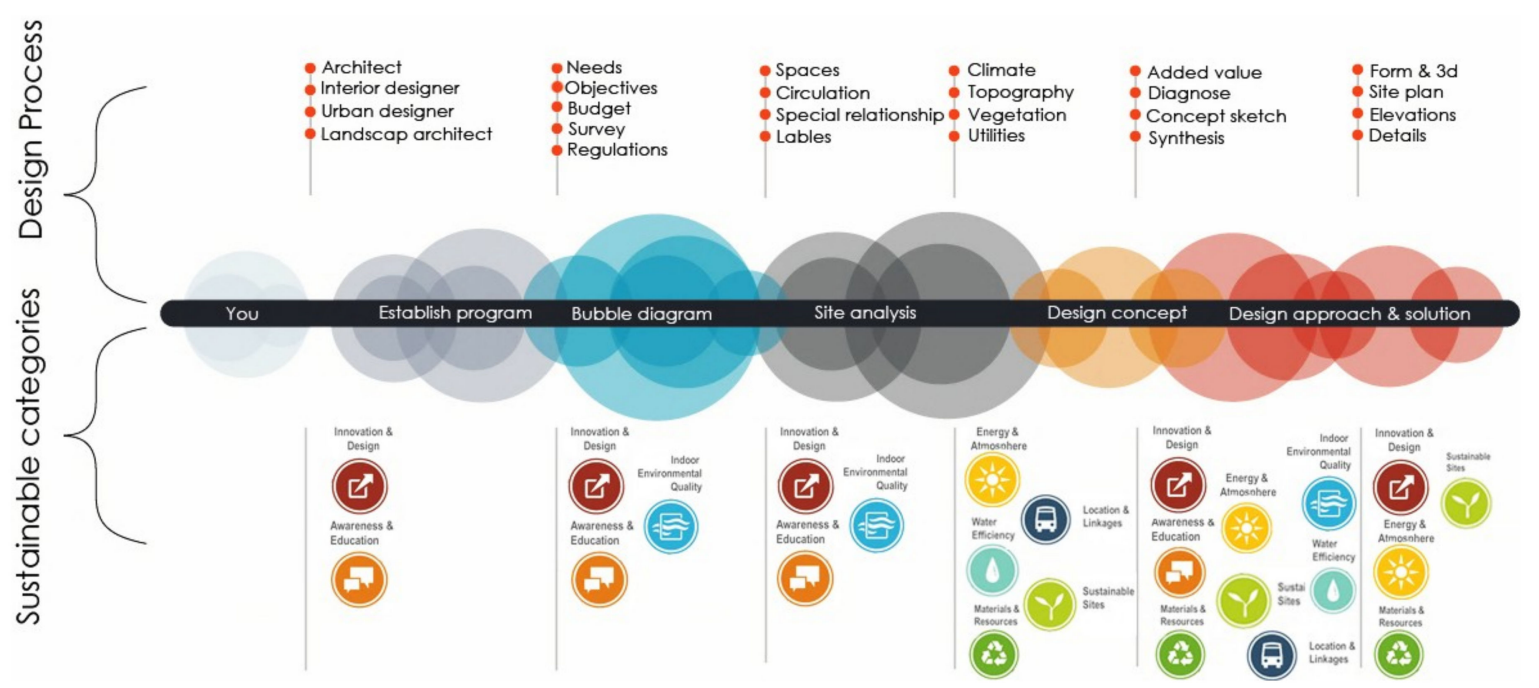

Figure 23. Guidelines categories manual for designers. Adapted from [19].

\section{Conclusion}

Generally, in order to develop something and to improve it, it is necessary to learn from previous experiences, to learn from the past, especially when talking about a very rich background and a very poor reality. In this paper, some strategies were raised and explored in building design scale, both in the old and new contexts, comparing the old and the contemporary city areas of Nablus.

The study tried to highlight these strategies in order to assess their potential to use them in improving the design of new urban areas. This study focused on the building scale strategies and since urban scale strategies should also be studied. This will be developed in another study complementary to this one.

Using a comparative approach, this paper showed that some of vernacular Palestinian architecture's strategies have good potential to be used in the design of new buildings and urban areas in Palestine. These strategies must be used together with other contemporary design approaches and knowledge in order to satisfy inhabitant's needs and expectations, thus contributing to the creation of a more sustainable built environment.

From the results of this study, it is possible to highlight that vernacular strategies should be used as guidelines in contemporary urban planning and building design processes. Among others, future research should focus on the quantitative performance of different vernacular design principles and surveys to the building occupants in order to better understand how each principle can contribute to satisfying their expectations.

Author Contributions: Conceptualization, F.A.T.; Supervision, L.B. and R.M.; Writing—original draft, F.A.T.; Writing-review \& editing, F.A.T., L.B., and R.M.

Funding: This research was funded by the ERASMUS MUNDUS Peace II program.

Acknowledgments: The authors would like to thank Nablus Municipality for the help in the data collection.

Conflicts of Interest: The authors declare no conflict of interest.

\section{References}

1. Fernandes, J.; Dabaieh, M.; Mateus, R.; Bragança, L. The influence of the Mediterranean climate on vernacular architecture: a comparative analysis between the vernacular responsive architecture of southern Portugal and north of Egypt. In Proceedings of the World Sustainable buildings SB14, Barcelona, Spain, 28-30 October 2014.

2. Haddad, H. A Framework of Sustainable Design for the Region of Palestine; The Pennsylvania State University: State College, PA, USA, 2010.

3. Abu-Lughod, J.L. The Islamic city-Historic myth, Islamic essence, and contemporary relevance. Int. J. of Middle East Stud. 1987, 19, 155-176. [CrossRef] 
4. Stevenson, F.; Ball, J. Sustainability and materiality: The bioregional and cultural challenges to evaluation. Local environ. 1998, 3, 191-209. [CrossRef]

5. Galán-Marín, C.; López-Cabeza, V.P.; Rivera-Gómez, C.; Rojas-Fernández, J.M. On the Influence of Shade in Improving Thermal Comfort in Courtyards. Proceedings 2018, 2, 1390. [CrossRef]

6. Weber, W.; Yannas, S. Lessons from Vernacular Architecture; Routledge: Abingdon-on-Thames, UK, 2013; ISBN 1135015554.

7. Ijla, A.; Broström, T. The sustainable viability of adaptive reuse of historic buildings: The experiences of two world heritage old cities; Bethlehem in Palestine and Visby in Sweden. Int. Invent. J. of Arts and Soc. Sci. 2015, 2, 52-66.

8. Abdel Hadi, M. Possibility of developing Eco-Friendly residential buildings in the Palestinian cities-A case study from Jenin and Rammallah cities. Doctoral Dissertation in Architecture, An-Najah National University, Nablus, Palestine, 2013.

9. Hussein, M.H.; Barlet, A.; Semidor, C. Socio-Environmental Dimensions of Private Outdoor Spaces in Contemporary Palestinian Housing. Open House Int. 2010, 35, 67-76.

10. Itma, M. High-density housing in Palestine: learning from traditional typologies. The Sustain. City IX 2014, 191, 87-95.

11. Al Tawayha, F.; Bragança, L.; Mateus, R. Ecology and environment, an urban scale comparative study between contemporary and vernacular city of Nablus. In Proceedings of the SBE16 Brazil \& Portugal—Sustainable Urban Communities towards a Nearly Zero Impact Built Environment, Vitória, Brazil, 7-9 September 2016.

12. Meier, I.A.; Roaf, S.C.; Gileard, I.; Runsheng, T.; Stavi, I.; Mackenzie-Bennett, J. The vernacular and the Environment towards a comprehensive Research methodology. In Proceedings of the 21th Conference on Passive and Low Energy Architecture, Eindhoven, The Netherlands, 19-22 September 2004; pp. 719-724.

13. Azab, K. Residential architecture in Islamic civilization. Islam Today 2008, 25, 121-127.

14. Fernandes, J.; Mateus, R.; Bragança, L.; Correia da Silva, J.J. Portuguese vernacular architecture: The contribution of vernacular materials and design approaches for sustainable construction. Archit. Sci. Rev. 2015, 58, 324-336. [CrossRef]

15. Bouzir, T.A.K.; Zemmouri, N. Effect of urban morphology on road noise distribution. Energy Procedia 2017, 119, 376-385. [CrossRef]

16. Physical Techniques to Reduce Noise Impacts-FHWA. Available online: https://www.fhwa.dot.gov/ ENVIRonment/noise/noise_compatible_planning/federal_approach/audible_landscape/al04.cfm (accessed on July 15 2018).

17. Ardda, N.; Mateus, R.; Bragança, L. Methodology to Identify and Prioritise the Social Aspects to Be Considered in the Design of More Sustainable Residential Buildings-Application to a Developing Country. Buildings 2018, 8, 130. [CrossRef]

18. USGBC, T. Green Building Design and Construction: With global alternative compliance paths. Available online: https:/ /www.usgbc.org/sites/default/files/LEED\%202009\%20RG\%20BD+C-Supplement_ GLOBAL_10_2014_Update.pdf (accessed on 8 February 2019).

19. Lin, M.W. Drawing and Designing with Confidence: A Step-by-step Guide; John Wiley \& Sons: Hoboken, NJ, USA, 1993; ISBN 0471283908.

(C) 2019 by the authors. Licensee MDPI, Basel, Switzerland. This article is an open access article distributed under the terms and conditions of the Creative Commons Attribution (CC BY) license (http:/ / creativecommons.org/licenses/by/4.0/). 